

\title{
TECENDO REDES IMPERIAIS: UMA DIMENSÃO ASIÁTICA DO COMÉRCIO BRITÂNICO DE ESCRAVos no Atlântico no sÉculo XVIII*
}

\author{
Kazuo Kobayashi iD \\ Waseda University
}

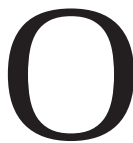

comércio de escravos no Atlântico é um dos assuntos mais bem pesquisados da história mundial. Com o fornecimento constante de mão de obra do continente africano, esse comércio foi importante para o desenvolvimento das economias coloniais de plantation nas Américas no início da era moderna. Os produtos das plantations escravistas, como açúcar, tabaco, índigo e algodão cru, abasteciam uma demanda insaciável dos consumidores e produtores têxteis europeus. De acordo com a estimativa do Slave Voyages, o banco de dados do comércio transatlântico de escravos, o século XVIII foi o auge desse comércio no Atlântico: 6,4 milhões de escravizados foram levados da África Atlântica e 71 mil da África Oriental. Os principais participantes do tráfico de escravos nesse século foram a Grã-Bretanha e Portugal, junto ao Brasil. Enquanto o império britânico liderava o tráfico de escravos no Atlântico Norte, o império português predominava no Atlântico Sul, transportando 2,2 milhões de escravos, quase todos para o Brasil. ${ }^{1}$

* Traduzido do inglês por Mariângela de Mattos Nogueira.

1 “Trans-Atlantic Slave Trade - Estimates”, Slave Voyages ש. Isso não significa que o comércio britânico de escravos no Atlântico se concentrasse exclusivamente em regiões ao redor do hemisfério norte e que os comerciantes lusófonos comercializassem apenas no hemisfério sul. Por exemplo, o golfo do Benim, na África Ocidental, foi a principal fonte de escravos para as minas de ouro brasileiras no primeiro terço do século XVIII. Ver Gustavo Acioli Lopes, "Brazil’s Colonial Economy and the Atlantic Slave Trade: Supply and Demand” in David Richardson e Filipa Ribeiro da Silva (orgs.), Networks and Trans-Cultural Exchange: Slave Trading in the South Atlantic, 1590-1867 (Leiden: Brill, 2014), p. 52. 
Os mercadores britânicos compraram 2,5 milhões de escravos na África Atlântica; 80\% deles foram levados para o Caribe Britânico e metade destes para a Jamaica.

Para comprar cativos africanos na costa atlântica, os mercadores estrangeiros tinham que oferecer o que os africanos desejavam. Como mostra a próxima seção, entre as mercadorias importadas na África Atlântica durante o século XVIII, os têxteis de algodão indianos eram um dos produtos mais procurados, pois tinham uma qualidade que atraía os consumidores locais. Portanto, os tecidos de algodão do sul da Ásia eram essenciais para europeus e brasileiros comerciarem escravos na África Ocidental. Este artigo examina o caso da Grã-Bretanha, o maior comerciante de escravos no Atlântico Norte durante o século XVIII, e discute como os tecidos de algodão para o comércio de escravos no Atlântico eram adquiridos. O artigo mostra que não apenas os consumidores africanos, mas também os produtores indianos exerceram influência no comércio britânico de longa distância e, portanto, no desenvolvimento de sua economia imperial atlântica. Isso nos permite desafiar a narrativa clássica do chamado "comércio triangular", que busca explicar o padrão de comércio da economia regional.

Seguindo a crítica de pesquisa anterior, este artigo descreve como a Companhia Britânica das Índias Orientais (English East India Company, EIC) adquiria têxteis de algodão no sul da Índia (a principal fonte desse produto, e em particular do tecido tingido de índigo) considerando as vicissitudes do Atlântico britânico, o comércio de escravos e a demanda do consumidor por têxteis indianos na África Ocidental. O artigo também discute a mudança no método de aquisição de têxteis indianos pela EIC, a partir do final do século XVIII, para mostrar como as formas de incentivo - um ponto chave que destaca o significativo protagonismo dos tecelões nas relações com a EIC - influenciaram o comércio atlântico da Grã-Bretanha. Além disso, serão apresentadas as rotas comerciais através das quais os têxteis indianos navegavam para a África Ocidental para serem trocados por escravos e produtos africanos. 


\section{Têxteis de algodão indiano na historiografia atlântica}

Para comprar cativos ao longo da costa da África Atlântica, era crucial para os compradores estrangeiros fornecerem bens que tinham demanda entre os consumidores locais. Essa demanda frequentemente se baseava em um valor cultural específico, no valor de uso para os consumidores e, em alguns casos, em motivações políticas, como ampliar a influência dos governantes que presenteavam seus súditos com produtos importados. ${ }^{2}$ Assim, as listas de mercadorias importadas pela África refletiam amplamente seus padrões de consumo.

Enquanto Eric Williams e Karl Polanyi observaram quais mercadorias eram demandadas na África Ocidental, Marion Johnson ofereceu um relato mais detalhado do consumo de bens importados na região. ${ }^{3}$ David Richardson examinou noventa relatos de viagens, partindo de Bristol e Liverpool, para explorar diferenças regionais de padrões de consumo na África Atlântica, mostrando que os têxteis eram o item de comércio mais importante na troca por produtos e escravos africanos no litoral do continente. ${ }^{4}$ Posteriormente, os historiadores investigaram a demanda por mercadorias em diferentes partes da África Atlântica. Por exemplo, Joseph

2 John Thornton, Africa and Africans in the Making of the Atlantic World, 1400-1800, $2^{\mathrm{a}}$ ed., Cambridge: Cambridge University Press, 1998, pp. 48-53. Este ponto tem sido bem discutido em estudos de caso de demanda do consumidor da África Oriental. Ver Jeremy Prestholdt, Domesticating the World: African Consumerism and Genealogies of Globalization, Berkley: University of California Press, 2008; Pedro Machado, Ocean of Trade: South Asian Merchants, Africa and the Indian Ocean c. 1750-1850, Cambridge: Cambridge University Press, 2014.

3 Eric Williams, Capitalism and Slavery, Chapel Hill: University of North Carolina Press, 1944; Karl Polanyi, "Sorting and 'Ounce Trade' in the West African Slave Trade”, Journal of African History, v. 5, n. 3 (1964), pp. 381-393; Marion Johnson, "The Atlantic Slave Trade and the Economy of West Africa” in Roger Anstey e Paul Edward Hedley Hair (orgs.), Liverpool, the African Slave Trade, and Abolition: Essays to Illustrate Current Knowledge and Research (Liverpool: Historic Society of Lancashire and Cheshire, 1976), pp. 14-38.

4 David Richardson, "West African Consumption Patterns and Their Influence on the Eighteenth-Century English Slave Trade” in Henry A. Gemery e Jan S. Hogendorn (orgs.), The Uncommon Market: Essays in the Economic History of the Atlantic Slave Trade (Cambridge: Academic Press, 1979), pp. 303-330. 
Miller, Roquinaldo Amaral Ferreira, Mariana Cândido, Gustavo Acioli e Maximiliano Menz, Daniel Domingues da Silva e, mais recentemente, Jesus Bohorquez investigaram o comércio luso-africano, revelando que havia uma grande demanda por têxteis indianos, que foram incorporados ao estilo de vida local entre o século XVIII e o início do século XIX. ${ }^{5}$ Philip Curtin, Michael Marcson, Roger Pasquier, James Webb Jr., Richard Roberts e eu exploramos o comércio francês com o Senegal, mostrando que os guinées, tecidos de algodão tingidos de índigo produzidos no sul da Ásia, foram importantes meios de troca ao longo do vale do rio Senegal, do final do século XVIII ao século XIX; embora os fabricantes da Europa Ocidental tenham tentado substituí-los por seus produtos mais baratos, feitos à máquina nos mercados globais. ${ }^{6}$ Em seu estudo de caso

5 Joseph C. Miller, “Imports at Luanda, Angola 1785-1823” in Gerhard Liesegang, Helma Pasch e Adam Jones (orgs.), Figuring African Trade: Proceedings of the Symposium on the Quantification and Structure of the Import and Export and Long Distance Trade in Africa 1800-1913 (Berlin: D. Reimer, 1986), pp. 163-246; Joseph C. Miller, Way of Death: Merchant Capitalism and the Angolan Slave Trade, 1730-1830, Madison: University of Wisconsin Press, 1996; Roquinaldo Amaral Ferreira, “Transforming Atlantic Slaving Trade, Warfare and Territorial Control in Angola, 1650-1800”, Tese (Doutorado), Universidade da California, Los Angeles, 2003, pp. 48-68; Mariana P. Candido, "Merchants and the Business of the Slave Trade at Benguela, 1750-1850”, African Economic History, n. 35 (2007), pp. 1-30; Gustavo Acioli e Maximiliano M. Menz, "Resgate e mercadorias: uma análise comparada do tráfico luso-brasileiro de escravos em Angola e na Costa da Mina (século XVIII)”, Afro-Ásia, n. 37 (2008), pp. 43-73; Daniel Domingues da Silva, The Atlantic Slave Trade from West Central Africa, 1780-1867, Cambridge: Cambridge University Press, 2017; Jesus Bohorquez, "Linking the Atlantic and Indian Oceans: Asian Textiles, Spanish Silver, Global Capital, and the Financing of the Portuguese-Brazilian Slave Trade (c. 1760-1808)”, Journal of Global History, v. 15, n. 1 (2020), pp. 19-38.

6 Philip D. Curtin, Economic Change in Precolonial Africa: Senegambia in the Era of the Slave Trade, Madison: University of Wisconsin Press, 1975; Michael D. Marcson, "European-African Interaction in the Precolonial Period: Saint Louis, Senegal, 1758-1854”, Tese (Doutorado), Universidade de Princeton, 1976; Roger Pasquier, "Les comptoirs du Sénégal au milieu du XIXe siècle” in Catherine CoqueryVidrovitch (org.), Actes du colloque entreprises et entrepreneurs en Afrique (XIXe et XXe siècle) (Paris: L’Harmattan, 1983), pp. 141-163; James L. A. Webb Jr., “The Trade in Gum Arabic: Prelude to French Conquest in Senegal”, Journal of African History, v. 26, n. 2 (1985), pp. 149-168; Richard Roberts, "West Africa and the Pondicherry Textile Industry” in Tirthankar Roy (org.), Cloth and Commerce: Textiles in Colonial India (Nova Delhi: Sage Publication, 1996), pp. 142-174; Kazuo Kobayashi, Indian Cotton Textiles in West Africa: African Agency, Consumer Demand and the Making of the Global Economy, 1750-1850, Cham: Palgrave Macmillan, 2019. Sobre o papel 
do Golfo do Benim, Robin Law também confirmou que os têxteis eram um dos principais itens comerciais e observou que a importância relativa dos diferentes tipos de têxteis mudou ao longo do tempo, acompanhando as mudanças na moda local. ${ }^{7} \mathrm{O}$ padrão geral do comércio anglo-africano de 1696 a 1808 está disponível no banco de dados compilado por Marion Johnson a partir dos registros alfandegários britânicos. Eles demonstram, quantitativamente, que os têxteis representaram de 60 a $70 \%$ do total das exportações da Grã-Bretanha para a África durante esse período e que os têxteis de algodão indianos se tornaram uma mercadoria emblemática no comércio a partir do segundo quarto do século XVIII - o que foi confirmado por Joseph Inikori. ${ }^{8}$ Colleen Kriger argumentou que o "pano da Guiné” feito na Índia era bem recebido na África Ocidental, porque era semelhante aos têxteis de algodão produzidos nos teares locais. ${ }^{9}$

monetário do tecido na África Centro-Ocidental e Ocidental pré-colonial, ver Lars Sundström, The Trade of Guinea, Uppsala: Studia Ethnographica Upsaliensia XXIV, 1965; Marion Johnson, “Cloth as Money: the Cloth Strip Currencies of Africa” in Dale Idiens e K. G. Ponting (orgs.), Textiles of Africa (Bath: Pasold Research Fund, 1980), pp. 193-202; Phyllis M. Martin, "Power, Cloth and Currency on the Loango Coast", African Economic History, n. 15 (1982), pp. 1-12; Carlos F. Liberato, "Money, ClothCurrency, Monopoly, and Slave Trade in the Rivers of Guiné and the Cape Verde Islands 1755-1777” in Catherine Eagleton, Harcourt Fuller e John Perkins (orgs.), Money in Africa (Londres: British Museum Press, 2009), pp. 9-19; Linda Newson, "The Slave-Trading Accounts of Manoel Batista Peres, 1613-1619: Double-Entry Bookkeeping in Cloth Money”, Accounting History, v. 18, n. 3 (2013), pp. 343-365.

7 Robin Law, The Slave Coast of West Africa, 1550-1750: The Impact of the Atlantic Slave Trade on an African Society, Oxford: Oxford University Press, 1991, pp. 201-202.

8 Marion Johnson, Anglo-African Trade in the Eighteenth Century: English Statistics on African Trade 1699-1808, Leiden: Centre for the History of European Expansion, 1990; Joseph E. Inikori, Africans and the Industrial Revolution in England: A Study in International Trade and Economic Development, Cambridge: Cambridge University Press, 2002; Joseph E. Inikori, "English Versus Indian Cotton Textiles: The Impact of Imports on Cotton Textile Production in West Africa” in Giorgio Riello e Tirthankar Roy (orgs.), How India Clothed the World: The World of South Asian Textiles, 1500-1850 (Leiden: Brill, 2009), pp. 85-114.

9 Colleen E. Kriger, “Guinea Cloth: Production and Consumption of Cotton Textiles in West Africa before and during the Atlantic Slave Trade” in Giorgio Riello e Prasannan Parthasarathi (orgs.), The Spinning World: A Global History of Cotton Textiles, 1200-1850 (Oxford: Oxford University Press, 2009), pp. 105-126; Coleen E. Kriger, Cloth in West African History, Lanham: AltaMira Press, 2006. Pano da Guiné era um termo genérico para os tecidos de algodão produzidos no sul da Ásia e vendido para 
Entretanto, Stanley Alpern fez uma lista de produtos comerciais em que mencionava mais de três dúzias de tipos diferentes de tecidos de algodão indianos exportados para a África durante a era do comércio de escravos no Atlântico. ${ }^{10}$

Essas obras mostram claramente que a expansão do comércio de escravos, de modo a atender à demanda nas Américas por mão de obra para produzir bens de plantation e minerar prata e ouro para a Europa, dependia da demanda da África Atlântica por bens importados. Indicam ainda que os têxteis indianos desempenharam um grande papel no tráfico atlântico de escravos durante o século XVIII, em particular a partir do segundo quarto do século. Em outras palavras, os tecelões indianos foram capazes de responder com eficácia à demanda do consumidor na África Atlântica por seus manufaturados. Esse vínculo entre a África ao sul do Saara e o Sul da Ásia - ou o que chamo de "vínculo econômico sul-sul”, estabelecido com a expansão imperial do início da era moderna proporcionou a base para a expansão do comércio de escravos e, portanto, o desenvolvimento da economia atlântica baseada na escravidão no século XVIII. ${ }^{11}$

Essa perspectiva também nos ajuda a substituir o conceito clássico do padrão do comércio atlântico dos primeiros tempos modernos: o comércio triangular. Esse modelo foi amplamente discutido em Capitalism and Slavery, de Eric Williams. Com a Grã-Bretanha (e, em menor medida, com a França) em mente, Williams mostrou que esses países europeus, fornecedores de "produtos de exportações e navios" para o comércio de escravos, conectavam a África Atlântica, fonte de “mercadorias humanas”, com as Américas, principalmente o Caribe

a África Ocidental. Ver John Irwin e P. R. Schwartz, Studies in Indo-European Textile History, Ahmedabad: Calico Museum of Textiles, 1966, p. 65.

10 Stanley B. Alpern, "What Africans Got for Their Slaves: A Master List of European Trade Goods”, History in Africa, v. 22 (1995), pp. 5-43.

11 Mesmo no início do século XIX, essa ligação permaneceu essencial no comércio de não escravos entre a França e o Senegal, assim como no surgimento da economia global moderna. Ver Kobayashi, Indian Cotton Textiles in West Africa. 
Britânico, cujas plantations produziam bens primários. É bem conhecido o argumento provocativo de Williams, que considera que os lucros do comércio triangular tiveram múltiplos efeitos sobre o desenvolvimento da economia inglesa, em especial sobre o crescimento da indústria do algodão em Manchester.

Embora o próprio Williams tenha reconhecido a importância dos têxteis de algodão indianos para a compra de escravos na África, esse modelo triangular não acomoda de forma satisfatória o papel do comércio Europa-Ásia como fornecedor do que estava em grande demanda na África Ocidental do século XVIII. Como foi observado acima, isso ocorre porque Williams estava tentando explicar o comércio de escravos e sua influência na revolução industrial da Inglaterra e não pretendia tratar do comércio global de algodão. ${ }^{12}$ Entretanto, como vimos, foram os têxteis de algodão indiano que facilitaram, e muito, o tráfico de escravos no Atlântico. Além disso, considerando o fato de que os fabricantes em Manchester competiam com os tecelões indianos na produção de tecidos de algodão para atender ao gosto do consumidor da África Ocidental, desconsiderar a dimensão asiática na economia atlântica é enganador.

A esse respeito, uma vez que a narrativa do comércio triangular ainda é hegemônica nos estudos atuais, Giorgio Riello propôs, recentemente, um novo modelo de "sistema em forma de diamante" para integrar a dimensão asiática, ou seja, a reexportação de têxteis indianos, ao modelo de três lados do comércio atlântico. ${ }^{13}$

A fim de destacar os papéis dos consumidores africanos e dos tecelões indianos no sistema global de troca, a ligação econômica sul-sul discutida neste artigo pode aprimorar a análise das relações transoceânicas entre a África Atlântica e o sul da Ásia. Ambos os atores são geralmente subalternos nos estudos históricos, mas seu protagonismo moldou o desenvolvimento do comércio atlântico e da economia britânica de

12 Williams, Capitalism and Slavery.

13 Giorgio Riello, Cotton: The Fabric that Made the Modern World, Cambridge: Cambridge University Press, 2013, p. 148. 
maneiras diferentes. O gosto dos consumidores na África influenciava o comércio europeu e determinava o tipo de tecido a ser produzido pelos tecelões do sul da Ásia, como cor, desenho, cheiro e outros. Atender a esse gosto era crucial para que os europeus pudessem comprar cativos e produtos na costa atlântica da África. É importante notar também que a conexão comercial entre essas duas regiões era mediada por comerciantes europeus. Eles adquiriam tecidos de algodão no sul da Ásia e os exportavam para a África Atlântica por meio de suas rotas comerciais. No caso da Grã-Bretanha, a EIC era o principal fornecedor de tecidos de algodão para o comércio de escravos - a companhia desfrutou do monopólio do comércio com a Ásia enquanto a Grã-Bretanha participou do comércio de escravos no Atlântico.

Como a EIC adquiria têxteis de algodão no sul da Ásia para comerciar na África Atlântica no século XVIII? Há uma quantidade substancial de estudos originais sobre a aquisição e importação de têxteis indianos para os mercados britânicos durante esse século. Eles cobrem vários aspectos do processo de aquisição do produto: a distribuição geográfica do algodão cru; a indústria têxtil em relação à organização social e estrutura da produção; as rotas comerciais das áreas de produção para Londres; as mudanças institucionais da EIC no sistema de aquisição e o retorno ao tecelão. ${ }^{14}$ Embora esses estudos tenham revelado esses

14 Sobre a aquisição de têxteis pela EIC na Índia em geral, ver K. N. Chaudhuri, "The Structure of Indian Textile Industry in the Seventeenth and Eighteenth Centuries”, Indian Economic and Social History Review, v. 11, n. 2-3 (1974), pp. 127-182; K. N. Chaudhuri, The Trading World of Asia and the English East India Company, 1660-1760, Cambridge: Cambridge University Press, 1978, cap. 11. Sobre Bengala, ver Hossain Hameeda, The Company Weavers in Bengal: The East India Company and the Organization of Textile Production in Bengal, 1750-1813, Dhaka: University Press, 2010; Om Prakash, "From Market-Determined to CoercionBased Textile Manufacturing in Eighteenth-Century Bengal” in Giorgio Riello e Tirthankar Roy, How India Clothed the World (Leiden: Brill, 2009), pp. 217-251. Sobre a Índia ocidental, Lakshmi Subramanian, "Power and the Weave: Weavers, Merchants and Rulers in Eighteenth-Century Surat” in Rudrangshu Mukherjee e Lakshmi Subramanian (orgs.), Politics and Trade in the Indian Ocean World: Essays in Honour of Ashin Das Gupta (Delhi: Oxford University Press, 1998), pp. 52-79. Sobre o sul da Índia, ver S. Arasaratnam, "Weavers, Merchants and Company: The Handloom Industry in Southeastern India, 1750-1790”, Indian Economic and 
aspectos da aquisição de têxteis no Sul da Ásia para a Grã-Bretanha, nosso conhecimento sobre a aquisição desses bens para o comércio com a África Ocidental ainda é muito limitado. ${ }^{15}$ Isso se deve principalmente ao fato de que a pesquisa acadêmica tende a se concentrar no comércio anglo-asiático. Os têxteis de algodão indianos para a África Ocidental receberam apenas uma atenção superficial na literatura. Por exemplo, K. N. Chaudhuri mencionou que a EIC leiloou têxteis indianos em Londres para a Europa continental, as Américas e a África Ocidental na primeira metade do século XVII. ${ }^{16} \mathrm{H}$. V. Bowen também observa brevemente que a demanda por tecidos de algodão indianos na África Ocidental aumentou no início dos anos $1760 .{ }^{17}$ Essa lacuna na literatura serve de justificativa para este artigo.

Social History Review, v. 17, n. 3 (1980), pp. 257-281; Joseph Brennig, "Textile Producers and Production in Late Seventeenth Century Coromandel", Indian Economic and Social History Review, v. 23, n. 4 (1986), pp. 333 355; Sanjay Subrahmanyam, "Rural Industry and Commercial Agriculture in Late SeventeenthCentury South-Eastern India”, Past and Present, n. 126 (1990), pp. 76-126; Prasannan Parthasarathi, The Transition to a Colonial Economy: Weavers, Merchants and Kings in South India, 1720-1800, Cambridge: Cambridge University Press, 2001; Potkuchi Swarnalatha, The World of the Weaver in Northern Coromandel: c. 1750 - c.1850, Hyderabad: Orient Longman, 2005; S. Jeyaseela Stephen, Oceanscapes: Tamil Textiles in the Early Modern World, Delhi: Primus Books, 2014, pp. 321-386; Giorgio Riello, "Factories before the Factory: The English East India Company's Textile Procurement in India and British Industrialisation, 1650-1750” in Kristine Bruland, Anne Gerritsen, Pat Hudson e Giorgio Riello (orgs.), Reinventing the Economic History of Industrialisation (Montreal: McGill-Queen's University Press, 2020), pp. 262-275.

15 Este é particularmente o caso quando comparado com a aquisição de têxteis indianos para a África Oriental. Sobre isso, Pedro Machado discute as conexões entre Gujarat (norte da Índia) e o leste da África. Machado, Ocean of Trade.

16 Chaudhuri, The Trading World, p. 132; K. N. Chaudhuri, The English East India Company: The Study of an Early Joint-Stock Company 1600-1640, Londres: Frank Cass, 1965, pp. 147-150.

17 H. V. Bowen, The Business of Empire: The East India Company and Imperial Britain, 1756-1833, Cambridge: Cambridge University Press, 2005, pp. 238-239. 


\section{A aquisição de tecidos de algodão no sul da Índia ${ }^{18}$}

Esta seção ilustra o sistema de aquisição de têxteis de algodão pela EIC no sul da Índia com base no exame da literatura e das fontes originais disponíveis na Biblioteca Britânica, em Londres, e no Arquivo do Estado de Tâmil Nadu (antigo Escritório de Registro de Madras) em Chennai. ${ }^{19}$ A Costa de Coromandel, no sul da Índia, uma das quatro principais regiões têxteis de algodão do subcontinente, era conhecida no início do período moderno pelos produtos tecidos à mão, brancos e coloridos (geralmente, azuis ou vermelhos), destinados à África Ocidental. Têxteis de algodão de cor azul eram conhecidos como bafts ou mais simplesmente blue goods $e$ blue cloths. A Costa de Coromandel também era conhecida pelo corante vermelho da raiz chaya (Oldenlandia umbellata), bem como o oeste da Índia pela morinda, cuja alizarina permitia que artesãos locais produzissem tecidos de cor vermelha. ${ }^{20}$

Um dos principais têxteis fabricados no sul da Índia era o tecido longo. No início do século XVII, este era tecido principalmente em Golconda, no norte de Coromandel, e, mais tarde, passou a ser produzido em toda a região tâmil. Radhika Seshan observa que o tecido longo era “talvez o único tecido típico de Coromandel”. Este tipo de tecido era “o de melhor qualidade ou o ‘superfino’ branco liso” da região e era conhecido por ser excepcionalmente longo (cerca de 37 jardas), com 11/4 jardas de largura. Outro tipo era o sallampore, que também era inicialmente tecido em Golconda e, posteriormente, em várias partes da região tâmil. Esse tipo de tecido era geralmente produzido em 16 jardas de comprimento

18 Uma discussão mais detalhada das duas seções a seguir aparece no Capítulo 4 do livro deste autor publicado em 2019.

19 As outras duas regiões são Punjab e Gujarat, no norte da Índia, e Bengala no leste da Índia. Chaudhuri, “The Structure of Indian Textile Industry”, pp. 36-48.

20 Mattiebelle Gittinger, Master Dyers to the World: Technique and Trade in Early Indian Dyed Cotton Textiles, Washington, DC: The Textile Museum, 1982, pp. 19-21; Swarnalatha, The World of the Weaver, pp. 21-29. 
e uma jarda de largura. ${ }^{21}$ Cuddalore e Salem, no distrito de South Arcot, foram, a princípio, os principais centros de produção desses tecidos no sul de Coromandel e, no início do século XIX, Nagore tornou-se uma fonte alternativa. ${ }^{22}$ Esses lugares também produziam têxteis de cor vermelha, mas, aparentemente, os produtos azuis dominaram o comércio com a EIC. ${ }^{23}$ Uma carta dessa companhia ao presidente do conselho em Fort St. George, em Madras, observou que, mesmo que o investimento em Cuddalore não fosse bem-sucedido, era "altamente necessário suprir a deficiência de produtos azuis de Nagore”, uma vez que o tingimento era superior ao padrão para a África Ocidental e seu odor também era muito apreciado. $^{24}$

No sul da Índia, as informações sobre as demandas dos mercados africanos eram transmitidas por meio de uma rede de intermediários que incluía a Junta Administrativa da EIC em Londres, a Diretoria Comercial em Fort St. George, em Madras, e os residentes comerciais da companhia. Os residentes comerciais tinham sob seu controle os lavadores, tecelões e tintureiros que trabalhavam para a EIC. Devido à ausência de fontes confiáveis, é virtualmente impossível especificar como essas informações chegavam da África Ocidental, passando pela Grã-Bretanha, até a Índia. No entanto, algumas fontes de arquivo mostram conexões entre a demanda

21 Irwin e Schwartz, Studies in Indo-European Textile History, p. 39, 67, 70; Radhika Seshan, Trade and Politics on the Coromandel Coast: Seventeenth and Early Eighteenth Centuries, Delhi: Primus Books, 2012, p. 15; Stephen, Oceanscapes, pp. 615-616.

22 British Library (BL), Londres, India Office Records (IOR), E/4/888, Madras dispatch, 9 set. 1801, p. 655. Aparentemente, Salem tornou-se um importante centro de tecelagem no final do século XVII ou início do século XVIII. O distrito de Arcot era conhecido pelo solo negro adequado ao cultivo de algodão cru necessário para a indústria têxtil. Sanjay Subrahmanyam, The Political Economy of Commerce: Southern India, 1500-1650, Cambridge: Cambridge University Press, 1990, p. 71.

23 BL, IOR E/4/904, Madras dispatch, 16 jan. 1810, p. 478.

24 BL, IOR E/4/895, Madras dispatch, 19 jun. 1805, pp. 75-76; BL, IOR E/4/901, Madras dispatch, 6 mar. 1807, p. 747. O odor dos produtos azuis aparentemente vinha do índigo usado na Índia, e os produtos provavelmente eram entregues aos consumidores africanos sem lavagem após o tingimento, caso contrário, o cheiro do índigo teria desaparecido. Os consumidores da Africa Ocidental prefeririam produtos novos. Kobayashi, Indian Cotton Textiles in West Africa, pp. 84-86. 
da África Ocidental e a produção têxtil no sul da Índia do século XVIII ao início do século XIX.

Os diretores da EIC informavam à Junta Comercial sobre as situações do mercado e que tipos de tecidos de algodão, incluindo comprimento e cor, eram necessários. Por exemplo, em resposta ao fim da Guerra dos Sete Anos, que reviveu o comércio de escravos no Atlântico, os diretores solicitaram ao Fort William em Bengala, ao Fort St. George em Madras e ao Conselho em Bombaim o fornecimento de artigos de tear manual para que Londres comprasse escravos na África Ocidental. Entre eles, por exemplo, a carta ao Fort St. George enfatizava que "não deveriam, de forma alguma, excluir o envio de toda a quantidade de tecidos longos, sallampores azuis, pois eles, em particular, são muito desejados [na África Ocidental]”. ${ }^{25}$

A Junta Comercial de Madras informava aos residentes comerciais em Cuddalore, e outros lugares, que tipos de têxteis eram exigidos pela EIC. Eles raramente revelavam os destinos finais, ou a situação do mercado, para têxteis indianos de tipos específicos. ${ }^{26}$ Portanto, os intermediários e tecelões indianos provavelmente não sabiam que alguns de seus produtos chegavam à África Ocidental via Londres.

Em todo caso, a Junta Comercial queria um fornecimento regular de têxteis de qualidade aceitável para Londres. Eles verificavam cuidadosamente a textura, espessura, cor, variedade e odor desses artigos de tear manual comparando os padrões das mercadorias entregues das aldeias de tecelagem para os assentamentos comerciais na costa. ${ }^{27}$ Na realidade, os produtos de tear manual variavam em qualidade, e os

25 BL, IOR E/4/863, Madras dispatch, 15 fev. 1765, p. 79; BL, IOR E/4/997, Carta de Londres para Bombaim, 22 mar. 1765, pp. 611-612; C. S. Sriktivasachari (org.), Fort William-India House Correspondence and Other Contemporary Papers Relating Thereto, v. 4: 1764-1766, Delhi: National Archives of India, 1962, p. 92.

26 Tamil Nadu State Archives (MRO), Chennai, South Arcot, 100/18464, Carta de Edward Holland, 28 maio 1794, em uma carta de J. William Junior para John Kentworthy, Fort St. George, 19 jan. 1795.

27 MRO, South Arcot, 100/18464, Carta de Fallofield para Kentworthy, Fort St. George, 1 maio 1795. 
tecidos que não atendiam aos padrões de qualidade eram rejeitados pela Junta Comercial. ${ }^{28}$ Isso implicava que as compras da EIC para os mercados da África Ocidental dependiam muito do desempenho dos tecelões indianos, que por sua vez dependiam do preço das matérias-primas e dos alimentos, do acesso à água e das condições ecológicas.

O sistema de compra prevalente no sul da Índia, bem como em outras partes daquele país, até meados do século XVIII, foi chamado por Chaudhuri de "sistema de adiantamento". Este não era o mesmo que o sistema de distribuição, em que os comerciantes forneciam aos tecelões matéria-prima, e não dinheiro, para que pudessem controlar o capital e para que os tecelões não se tornassem financeiramente independentes. Em contraste, o sistema de adiantamento permitia que os produtores têxteis mantivessem, até certo ponto, sua independência para determinar como gastar o dinheiro adiantado na produção têxtil e escolher sua própria forma de sustento. ${ }^{29}$

O pano de fundo desse sistema era o fato de a EIC não ter conseguido entrar nas aldeias de tecelões e estabelecer contato direto com eles devido à barreira da língua. Portanto, uma solução para o sistema de adiantamento foi o uso de intermediários indianos, que conectavam as aldeias dos tecelões ao mercado de exportação na costa. Alguns vinham das próprias aldeias. ${ }^{30}$ Os comerciantes indianos, como intermediários, forneciam crédito aos artesãos e têxteis para o mercado de exportação fora das aldeias. O lucro que obtinham com esse comércio era de 4 a 5\%, no máximo. Isso permitia que a EIC comprasse a um custo baixo e, assim,

28 Os despachos anuais do Tribunal de Administração em Londres para o Departamento Comercial de Fort St. George em Madras incluíam comentários e avaliações sobre os têxteis adquiridos na Presidência de Madras.

29 O adiantamento de matérias-primas foi organizado no oeste da Índia do século XVIII, mas era excepcional. Chaudhuri, The Trading World, pp. 253-262. Para a extinção do sistema, ver Brennig, “Textile Producers”, pp. 350-351.

30 Para diferentes pontos de vista sobre os intermediários no sul da Índia antes de 1800, ver Vijaya Ramaswamy, “The Genesis and Historical Role of the Master Weavers in South India Textile Production”, Journal of the Economic and Social History of the Orient, v. 28, n. 3 (1985), pp. 294-325; Brennig, “Textile Producers”, pp. 333-355. 
os têxteis indianos permaneceram altamente lucrativos para eles até o século XVIII. ${ }^{31}$

Nas aldeias dos tecelões, também havia corretores. Alguns deles eram tecelões-chefes, que agiam como intermediários entre os tecelões e os comerciantes locais. No norte do rio Godavari, essas pessoas eram conhecidas como kopudarudu ou copdar (empreiteiro) e tinham alguma influência sobre os tecelões. Recebiam uma comissão de 3 a 5\% dos comerciantes locais, clientes da EIC, e geralmente compravam têxteis dos tecelões ou adiantavam empréstimos mediante empenho de seus teares. Além disso, eles ajudavam os tecelões em tempos de dificuldades e forneciam alimentos a um preço mais vantajoso. ${ }^{32}$

No sistema de adiantamento, porém, havia um problema entre os corretores e a EIC. Frequentemente, estes faziam acordos com outros compradores que não a EIC. Por exemplo, no final do século XVIII, Edward Holland, o então vice-secretário da Presidência de Madras, relatou que, uma vez que a EIC havia rejeitado os produtos de qualidade um tanto inferior, os corretores forneceram esses produtos aos franceses em Pondicherry. Essa prática dos corretores resultava da competição entre países europeus por têxteis de algodão ao longo da costa indiana. Esse comportamento frustraria a EIC e forneceria um motivo para a consolidação do seu controle sobre a aquisição de têxteis daí em diante. ${ }^{33}$

Assim, uma das características cruciais do sistema de adiantamento era permitir que os tecelões usassem o dinheiro adiantado para várias necessidades, como matéria-prima para tecer, alimentos para seus familiares, manutenção do tear e várias outras, como bem entendessem. Esse sistema também oferecia aos tecelões a chance de maximizar seus lucros, escolhendo o fio pelo preço mais barato. A maior parte do dinheiro adiantado normalmente ia para comida. Portanto, a qualidade de seus

31 Arasaratnam, "Weavers, Merchants and Company", p. 264.

32 Swarnalatha, The World of the Weaver, p. 77.

33 MRO, South Arcot, 100/18464, Carta de Edward Holland para o residente em Cuddalore, Fort St. George, 28 maio 1794. Ver também BL, IOR E/4/880, Madras dispatch, 28 maio 1794, p. 745. 
produtos acabados poderia variar de acordo com o preço do arroz e não apenas do algodão, pois eles tinham que lidar com a quantidade limitada de dinheiro para produzir os bens encomendados. ${ }^{34}$ Em outras palavras, um lado da ligação econômica sul-sul dependia da escolha dos tecelões indianos.

O fornecimento de têxteis de algodão indiano da EIC para Londres nem sempre atendia à demanda dos comerciantes que negociavam com a África Ocidental. Por exemplo, por volta de 1770, a EIC não pôde fornecer quantidade suficiente de panos indianos azuis para comerciantes que investiam no comércio de escravos. Um deles foi o comerciante londrino Gilbert Ross, investidor no comércio de escravos com a Senegâmbia. Ele solicitou ao Tesouro Nacional uma licença para comprar e comercializar milhares de peças de tecidos de algodão indianos em Roterdã. ${ }^{35}$ Em sua petição de 10 de outubro de 1770, Ross e outros comerciantes alegaram que “os panos longos azuis da Índia Oriental são absolutamente necessários para levar a cabo o comércio com a Senegâmbia e perfazer mais de três quartos do valor de todas as mercadorias exportadas para lá. [...] Não há nenhum substituto para o referido artigo”. Eles perderiam a temporada do comércio de goma na Senegâmbia, a menos que pudessem garantir, imediatamente, uma quantidade suficiente de produtos de algodão indianos daquele tipo. Ainda mencionaram que, além da Senegâmbia, "há também uma demanda anual muito considerável para o referido artigo [tecidos longos azuis indianos] em outras partes da África”. ${ }^{36}$ No pedido de permissão para fazer compras legalmente em Roterdã eles citaram “um

34 Arasaratnam, "Weavers, Merchants and Company”, p. 268.

35 No século XVIII, os portos holandeses como Roterdã foram uma fonte alternativa de têxteis de algodão indianos para os comerciantes ingleses que negociavam com a África. BL Add. Ms. 25503, Minutes of the South Sea Company, 21 fev. 1729, p. 385.

36 BL, IOR E/1/54, Petição ao Comissário do Tesouro de Sua Majestade de Gilbert Ross, James Mill, William Crichton, John Shoollred e Thomas Bell, Londres, 10 out. 1770 , pp. 250-252. Sobre a importância da goma arábica na indústria britânica no século XVIII, ver Maxine Berg, "In Pursuit of Luxury: Global History and British Consumer Goods in the Eighteenth Century”, Past and Present, n. 182 (2004), pp. 85-142. 
Ato de Sua Majestade intitulado Ato para promover mais eficazmente o comércio de exportação deste Reino para África etc.”, como segue:

Sempre que a Companhia Britânica das Índias Orientais [EIC], a qualquer momento, recusar-se a manter este mercado abastecido com uma quantidade suficiente de tais bens a preços razoáveis para atender ao comércio africano, ou negligenciá-lo, deve e pode ser permitido aos Senhores Comissários do Tesouro, em número de três ou mais, ou ao Lorde Alto Tesoureiro, por tempo indeterminado ou até quando julguem adequado, conceder licenças a qualquer outra pessoa ou pessoas para importar tais mercadorias para qualquer porto de Grã-Bretanha desde quaisquer portos da Europa para além dos domínios de Sua Majestade da mesma maneira e com as mesmas restrições e limitações por este ato prescritas e obrigadas. ${ }^{37}$

À medida que a demanda por têxteis indianos do mundo atlântico aumentou no final do século XVIII, incluindo a da África Ocidental para o comércio de escravos no Atlântico, a aquisição de têxteis de algodão na Índia tornou-se um problema sério para a EIC. Por exemplo, a escassez de alimentos em Madras, de 1790 a 1792, afetou a produção de tecidos de algodão na região. ${ }^{38}$ Os preços do fio e do índigo aumentaram em Cuddalore (o preço do fio aumentou de 50 a 60\%). John Kentworthy, residente comercial em Cuddalore, escreveu a Ernest William Fallofield, presidente da Junta Comercial de Madras, que o aumento no preço desses materiais e a "diferença de cor” causaram "uma degradação geral em quase todos os artigos de Cuddalore”. ${ }^{39}$

Além disso, é importante notar que a EIC enfrentou condições adversas na Grã-Bretanha e na Ásia neste período: uma séria escassez

37 BL, IOR E/1/54, Petição ao Comissário do Tesouro.

38 Stephen, Oceanscapes, p. 364.

39 MRO South Arcot 100/18464, Carta de John Kentworthy para Ernest William Fallofield, Cuddalore, 13 mar. 1795. Infelizmente, esta fonte descritiva não fornece os detalhes sobre a queda da qualidade dos têxteis. 
de capital na Índia na esteira das guerras carnáticas (1746-1763) e das guerras anglo-Maiçor (1767-1799). Esse problema financeiro levou a uma redução do investimento para aquisição de têxteis. Em 1790, a EIC investiu 1,6 milhão de pagodas para a compra de têxteis na costa tâmil, mas o investimento anual em têxteis caiu para 1,2 milhão de pagodas em $1796 .{ }^{40}$ Além disso, a ascensão da indústria do algodão em Lancashire representou um desafio. Os fabricantes emergentes desejavam novos mercados para seus têxteis, bem como fontes de matérias-primas (como algodão e índigo), e cada vez mais levantavam suas vozes em Downing Street pela proibição total da importação de têxteis indianos para a Grã-Bretanha. Em consequência disso, em 1774 o Parlamento Britânico proibiu as importações de produtos de algodão indianos, exceto chita simples e musselinas, e para a reexportação. ${ }^{41}$

\section{Do sistema de adiantamento ao sistema aumany no sul da Índia}

Como vimos acima, no final do século XVIII, as coisas não andavam bem para a EIC. Com a fonte financiadora limitada e as críticas ao monopólio comercial, a EIC teve que lidar com a melhoria e o controle da qualidade dos têxteis de algodão de exportação para a Grã-Bretanha. Quanto ao sul da Índia, à medida que os britânicos aumentavam sua influência como potência colonial, na década de 1770 , começaram a entrar nas aldeias de tecelões para estabelecer relações diretas entre a companhia e os tecelões. A EIC também tentou eliminar os intermediários indianos que, sob o sistema de adiantamento, eram os encarregados de trazer os tecidos acabados das aldeias do interior para a costa. Em vez disso, a companhia

40 Stephen, Oceanscapes, pp. 365-366. Pagode era uma moeda de ouro usada no sul da Índia.

41 Arasaratnam, "Weavers, Merchants and Company", p. 277; Anthony Webster, The Twilight of the East India Company: The Evolution of Anglo-Asian Commerce and Politics 1790-1860, Woodbridge: Boydell Press, 2009, pp. 24-33. 
empregou servos assalariados, chamados de gumastahs, como agentes indianos, para fazer adiantamentos aos tecelões e supervisionar os teares. No entanto, essa mudança institucional, realizada sob o nome de "sistema aumany”, encontrou hostilidade entre os tecelões, às vezes com violência. Por fim, a EIC não conseguiu romper a ligação entre os tecelões e os intermediários indianos. ${ }^{42}$

O sistema aumany era uma replicação do sistema que já havia sido introduzido em Bengala e em outros lugares, e implicava a gestão direta da terra e das vilas de tecelagem por um coletor. ${ }^{43}$ Sua aplicação objetivava a aquisição de têxteis de qualidade por meio de inspetores, conhecidos no sul da Índia como peons, indicados pela EIC. Esses inspetores substituíram os mercadores intermediários indianos que antes, sob o sistema de adiantamento, conectavam a EIC aos tecelões-chefes. Os inspetores conheciam as línguas locais, o que lhes permitia realizar todas as transações necessárias diretamente com os tecelões-chefes, sem intérpretes ou atrasos. ${ }^{44}$

Além disso, os tecelões, contratados pela EIC recebiam artigos de subsistência em vez do dinheiro adiantado no regime anterior. O sistema aumany pareceu à EIC "bem calculado para atender ao importante propósito de fornecer ao nosso comércio [em Londres] suprimentos amplos e regulares de peças de mercadoria”. ${ }^{45}$ Eles esperavam que esse novo sistema de compra

42 BL, IOR P/240/40, Carta de John Whitehill para Peter Baars de Jaggarnaikparam, Masulipatnam, 18 ago. 1775, Arasaratnam, "Weavers, Merchants and Company", pp. 271-274; e "Trade and Political Dominion in South India, 1750-1790: Changing British - Indian Relationships”, Modern Asian Studies, v. 13, n. 1 (1979), p. 30.

43 UK Parliament, Parliamentary Archives (UKPA), Londres, Parliamentary Papers, 1812, VII (397), The Fifth Report from the Select Committee on the Affairs of the East India Company, pp. 206-207; BL, IOR E/4/889, Madras dispatch, 23 jun. 1802, p. 703; MRO, South Arcot, 110/18474, Carta de Kinchant para Fallofield, Cuddalore, 15 jun. 1802. Para os casos de Bengala da Índia ocidental, ver Prakash, "Textile Manufacturing"; Hameeda, The Company Weavers; Subramanian, "Power and the Weave”; Swarnalatha, The World of the Weaver, p. 217.

44 MRO, South Arcot, 113/18477, Carta de C. Wynox para o Representante comercial em Caddalore, Fort St. George, 4 jan. 1804.

45 BL, IOR E/4/889, Madras dispatch, 23 jun. 1802, pp. 705, 710-711. 
pudesse, em última análise, interromper a fabricação de produtos de qualidade inferior se os contratantes fossem obrigados a entregá-los a nós com uma redução considerável de preço, estando também sujeitos a penalidades por conta de qualquer deficiência no padrão dos produtos. ${ }^{46}$

Em 1802, havia entre 15 e 20 aldeias no raio de 50 a 60 milhas de Cuddalore, com cerca de mil teares, com os quais eram produzidos lenços azuis e vermelhos, sallampores e outros. ${ }^{47}$ Richard Kinchant, residente comercial em Cuddalore, informou à Junta Comercial de Madras que o sistema aumany era “absolutamente necessário” para garantir tecidos de algodão. Uma das preocupações da EIC era proteger os interesses da companhia da ação de comerciantes europeus concorrentes. Para esse fim, os tecidos de qualidade inferior ao padrão eram "rejeitados e devolvidos aos tecelões, carimbando-se cada dobra com uma marca de rejeição para evitar que fossem novamente trazidos à companhia”. Além disso, a EIC pretendia controlar os tecelões, oferecendo-lhes certos benefícios, como "uma redução global do imposto aduaneiro sobre a linha”. ${ }^{48}$

Foi durante as Guerras Revolucionárias Francesas que o sistema aumany começou a entrar em vigor no sul da Índia. Apesar do aumento da demanda por produtos de algodão indiano na Europa Continental e na África Ocidental, a hostilidade francesa em relação à Grã-Bretanha tornou o fornecimento irregular. ${ }^{49}$ As guerras também afetaram tanto o comércio britânico quanto o consumo doméstico. Um despacho da EIC à Presidência de Madras afirmava que “devemos certamente esperar muitos inconvenientes com a guerra atual, enquanto ela continuar nossos ganhos serão muito reduzidos, já que nenhum produto, exceto os absolutamente

46 BL, IOR E/4/879, Madras dispatch, 25 jun. 1793, pp. 1009-1014.

47 MRO South Arcot 110/18474, Carta de Richard Kinchant para Fallofield, Cuddalore, 8 maio 1802.

48 MRO South Arcot 110/18474, Carta de Kinchant para Fallofield, Cuddalore, 15 jun. 1802; Carta de Kinchant para Fallofield, Cuddalore, 27 jul. 1802; Carta de Kinchant para John Wallace (Coletor de Tritchinopoly), Cuddalore, 26 dez. 1802.

49 BL, IOR E/4/884, Madras dispatch, 2 mar. 1798, pp. 141-143. 
necessários, encontrará compradores prontos para exportação”; e que o consumo de mercadorias, como chitas, deveria ser "muito pequeno" durante o período. ${ }^{50}$ Em tempo de guerra, o comércio de escravos do Atlântico britânico diminuiu em 40\%, de 46 mil escravos em 1793 para 27 mil escravos em 1794. O ano de 1794, em meio às guerras revolucionária e napoleônica, foi um dos mais fracos para esse comércio britânico. ${ }^{51}$

Sinnappah Arasaratnam observou que a EIC atingiu "um grau de controle sobre a indústria carnática de teares manuais em 1780". ${ }^{52}$ No entanto, como um todo, o sistema aumany parece ter funcionado contra a EIC. Deve ser lembrado que houve problema com incentivos. ${ }^{53}$ A EIC não deu aos tecelões incentivos suficientes para cumprirem suas obrigações contratuais, apesar do fato de terem recebido privilégios, como redução do imposto aduaneiro mensal sobre a linha. Os tecelões da Costa de Coromandel eram bastante itinerantes, podiam montar seus teares onde preferissem e se deslocar para onde encontrassem melhores condições. ${ }^{54}$ Eles escapariam do endividamento com a EIC e com os mercadores indianos fugindo para Pondicherry na virada do século XIX.

Ademais, o investimento da EIC na produção têxtil na Índia estava sujeito a circunstâncias locais e globais. Como já vimos, a política internacional na Europa e no mundo atlântico, por exemplo, afetaria a demanda. Além disso, os fabricantes britânicos tentaram desencorajar a EIC a importar têxteis de algodão da Índia para a Grã-Bretanha. Nesse ínterim, a instabilidade política (incluindo as guerras carnáticas e anglo-Maiçor e as disputas de castas) muitas vezes afetou o comércio de têxteis, já que, em circunstâncias como aquelas, os artesãos fugiam para áreas vizinhas

50 BL, IOR E/4/879, Madras dispatch, 25 jun. 1793, p. 946.

51 "Trans-Atlantic Slave Trade".

52 Arasaratnam, "Weavers, Merchants and Company”, p. 278.

53 Karolina Hutková discute, com mais detalhes, o problema de incentivos da EIC, com o caso da aquisição de seda crua em Bengala. Karolina Hutková, The English East India Company's Silk Enterprise in Bengal, 1750-1850: Economy, Empire and Business, Woodbridge: Boydell Press, 2019.

54 Irwin e Schwartz, Indo-European Textile History, pp. 31-32. 
mais seguras. E mais, havia intensa competição com outros comerciantes europeus e comerciantes privados locais pela compra de têxteis. E, como acontecia com o sistema de adiantamento, a variação no desempenho dos tecelões não pode ser negligenciada, uma vez que dependia do acesso à água para os processos de lavagem e tingimento; do mercado de matérias-primas - cujo preço também importava - e das condições ecológicas, incluindo desastres naturais e carência de alimentos. Seria justo, portanto, dizer que a eficácia do sistema aumany estava vinculada a tais contextos desde o início de sua introdução.

De fato, as evidências sugerem que o sistema aumany não necessariamente resolveu os problemas da companhia, em particular o da qualidade dos produtos. Quanto ao comércio com a África Ocidental, por exemplo, o ano de 1802 viu um crescimento da demanda por tecidos coloridos, especialmente os azuis lisos de Cuddalore e os sallampores azuis de Salem comercializados na Grã-Bretanha. No entanto, a companhia reclamou da incapacidade do residente comercial em Cuddalore de atender ao pedido da EIC para compra de têxteis. Em tal circunstância, esperava-se que Salem compensasse a deficiência de Cuddalore e que os longos panos azuis de Nagore também fossem considerados adequados para o mercado da África Ocidental. ${ }^{55}$

55 MRO, South Arcot, 109/18473, Carta de Holland para o Representante commercial em Cuddalore, Fort St. George, 3 set. 1802; BL, IOR E/4/889, Madras dispatch, 23 jun. 1802, pp. 765, 769-774. 
Gráfico 1

Transporte britânico de têxteis indianos para a África Ocidental e comércio de escravos britânico, 1772-1849

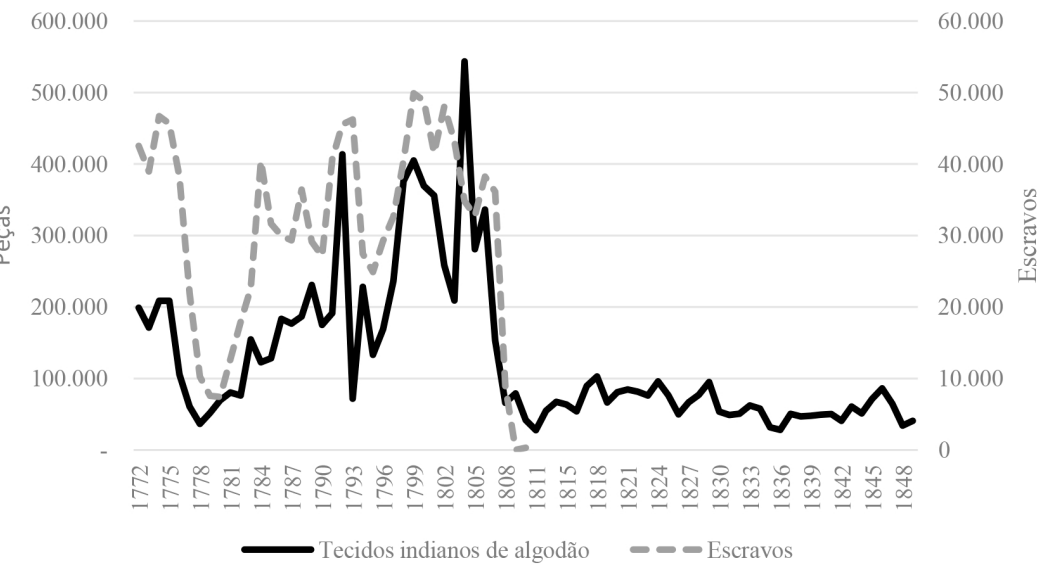

Fonte: Kobayashi, Indian Cotton Textiles, p. 167.

Em 1807, o Parlamento Britânico declarou ilegal o comércio de escravos, provocando um declínio no envio de têxteis de algodão indianos da Grã-Bretanha para a África Ocidental nos anos seguintes. O número de produtos de algodão indiano embarcados da Grã-Bretanha para a África Ocidental caiu de uma média de 256.800 peças em 18051807 para um mínimo de 27.800 peças em 1811 (Gráfico 1). ${ }^{56}$ A redução da demanda para o comércio com a África Ocidental fez com que a EIC reconsiderasse o investimento na produção têxtil na Presidência de Madras:

Em consequência da atual situação do comércio com a África, e alertando também para a carência de demanda nas Índias Ocidentais por produtos de peças coloridas normalmente destinados para lá, consideramos que nosso estoque de bens proibidos de todos os tipos, mas particularmente Blue Goods e Romals, é mais do que adequado para

56 The National Archives (TNA), Kew, CUST 17/27-29; CUST 10/3. As exportações de têxteis de algodão indianos da Grã-Bretanha para a África Ocidental foram de 281.000 peças em 1805, 336.000 peças em 1806 e 153.000 peças em 1807. 
qualquer demanda provável. Portanto, fomos forçados a limitar nossos investimentos em Masulipatam [Masulipatnam] e Cuddalore a somas muito insignificantes a seguir mencionadas e vimos ser necessário reduzir a quantidade de mercadorias a serem fornecidas em Nagore para cerca de trinta mil pagodas. ${ }^{57}$

Esta carta foi escrita para o Fort St. George em Madras, em 1812, apenas um ano após a depressão do comércio de têxteis indianos da Grã-Bretanha para a África Ocidental. ${ }^{58}$ Ela indica que a EIC planejava reduzir seu investimento na aquisição de têxteis de algodão no sul da Índia para os mercados do Atlântico, devido à redução da demanda dos negócios com a África Ocidental.

É preciso notar que a demanda por panos azuis entre os comerciantes africanos não necessariamente desapareceu durante a primeira metade do século XIX. O embarque de têxteis indianos continuou, especialmente o de produtos tingidos, da Grã-Bretanha para a África Ocidental, no início do século XIX, embora em menor quantidade do que antes. Na verdade, o comércio de têxteis de algodão indianos recuperou-se um pouco depois de 1811, e até 1830 a Grã-Bretanha despachou em média 75.000 peças de têxteis indianos para a África Ocidental, especialmente para Serra Leoa. ${ }^{59}$

57 BL IOR E/4/909, Madras dispatch, 3 jun. 1812, p. 187.

58 Masulipatnam era o principal distrito de produção têxtil para os mercados da Europa e da África Ocidental no norte de Coromandel, assim como Cuddalore no sul de Coromandel. Swarnalatha, The World of the Weaver, p. 22.

59 Na Alta Guiné, que engloba desde a Senegâmbia à Serra Leoa, durante o período pré-colonial, o tecido tingido de índigo funcionou como moeda corrente no mercado local. Em Serra Leoa, durante a primeira metade do século XIX, o tecido azul indiano era provavelmente trocado por madeira, sândalo africano, azeite de dendê e outros produtos. Kobayashi, Indian Cotton Textiles in West Africa. 


\section{Rotas de envio de têxteis de algodão do sul da Ásia para a África Atlântica}

Há uma lacuna lamentável na literatura sobre os têxteis de algodão indianos no comércio britânico de escravos no Atlântico: a exploração de rotas marítimas que transportavam têxteis de algodão do sul da Ásia através da Grã-Bretanha para a África Atlântica durante a era do comércio de escravos, em particular do final do século XVIII a 1807. Presumivelmente, o principal problema é que não há nenhum registro de vendas da EIC. Portanto, não podemos revelar a quais comerciantes a companhia vendeu tecidos de algodão indianos em seus leilões na cidade de Londres. No entanto, registros de comerciantes individuais podem lançar alguma luz sobre esse assunto pouco pesquisado. Um deles é a valiosa coleção de um comerciante londrino, Thomas Lumley, disponível no Arquivo Nacional do Reino Unido. Ele comprou têxteis indianos em leilões da EIC para si e seus parceiros de Liverpool, Londres e outros lugares, incluindo aqueles que investiam no comércio de escravos. Combinando as informações disponíveis nessa fonte com o banco de dados Slave Voyages, somos capazes de rastrear com precisão algumas rotas de transporte de têxteis indianos através da Grã-Bretanha para a África atlântica na década final do comércio britânico de escravos no Atlântico. ${ }^{60}$

Uma das coleções de Lumley no Arquivo Nacional é seu diário comercial, que cobre suas transações de 1801 a 1810. No seu conjunto, essa fonte sugere que suas transações anuais diminuíram ao longo da primeira década do século XIX, em consonância com a abolição do tráfico de escravos. No entanto, a atenção aos detalhes de seus registros nos permite descobrir que houve muitas transações de têxteis de algodão

60 Conforme informado pelo London Directory (1801-1808), Thomas Lumley trabalhava em Guitter Lane na cidade de Londres como negociante atacadista. Kazuo Kobayashi, "The British Atlantic Slave Trade and Indian Cotton Textiles: The Case of Thomas Lumley \& Co.” in Tomoko Shiroyama (org.), Modern Global Trade and the Asian Regional Economy (Singapore: Springer, 2018), pp. 59-85. 
indianos com seus parceiros: foram 130 em 1801; 125 em 1802; 61 em 1803; 64 em 1804; 52 em 1805; 54 em 1806 e 15 em 1807. Quanto às transações com seus sócios de Liverpool - até onde eu identifico -, houve (pelo menos) 35 transações (27\% do total) em 1801; 23 (18\%) em 1802; 14 (23\%) em 1803; 21 (33\%) em 1804; 14 (27\%) em 1805; 7 (13\%) em 1806 e nenhuma em $1807 .{ }^{61}$ Entre esses negociantes estavam mercadores de escravos, como as famílias Aspinall e Hinde, John Bolton e George Case. ${ }^{62}$ Eles compraram muito mais têxteis indianos de Lumley do que os outros parceiros que não investiam no comércio de escravos. ${ }^{63}$

O banco de dados Slave Voyages fornece informações detalhadas sobre o investimento desses comerciantes de Liverpool no comércio de escravos no Atlântico. A Tabela 1 é uma lista dos mercadores de Liverpool que compraram tecidos de algodão indianos de Lumley em 1801 para o comércio de escravos. Esses comerciantes são mostrados em ordem alfabética. Como está registrado no diário de Lumley em quais navios negreiros eles embarcaram as mercadorias indianas, é possível identificar pelo Slave Voyages seus itinerários e, portanto, os principais destinos onde esses tecidos de algodão foram trocados por escravos e produtos africanos na costa atlântica. Para fins práticos, a Tabela 1 concentra-se apenas

61 TNA C 114/154, Journal of Thomas Lumley \& Co., 1801-1807.

62 Os comerciantes listados no texto se associaram à Company of Merchants Trading to Africa, fundada em 1750 como sucessora da Royal African Company. Gomer Williams, History of the Liverpool Privateers and Letters of Marque with an Account of the Liverpool Slave Trade, Londres: William Heinemann, 1897, p. 679. Eles possuíam propriedades fora de Liverpool. David Pope, “The Wealth and Social Aspirations of Liverpool's Slave Merchants of the Second Half of the Eighteenth Century” in David Richardson, Suzanne Schwarz e Anthony Tibbles (orgs.), Liverpool and Transatlantic Slavery (Liverpool: Liverpool University Press, 2007), pp. 219-222. Sobre comerciantes individuais (por exemplo, a família Hinde), ver Melinda Elder, "Liverpool Slave Trade, Lancaster and its Environs” in David Richardson, Suzanne Schwarz, Anthony Tibbles (orgs.), Liverpool and Transatlantic Slavery (Liverpool: Liverpool University Press, 2010). George Case foi o pai do Liverpool Common Council, que era um reduto de conservadores e traficantes africanos no início do século XIX. Liverpool Mercury, 19 out. 1832.

63 Kobayashi, “The British Atlantic Slave Trade”, pp. 68-79. 
nos mercadores, seus navios e o principal local ou região de compra de escravos na África. ${ }^{64}$

Tabela 1

Comerciantes de Liverpool que compraram têxteis indianos de Lumley para o comércio de escravos em 1801

\begin{tabular}{|c|c|c|c|}
\hline Comerciante & Navio & $\begin{array}{c}\text { Principal região } \\
\text { de compra de escravos }\end{array}$ & $\begin{array}{c}\text { Voyage } \\
\text { ID }\end{array}$ \\
\hline John \& James Aspinall & Thomas & Bonny & 83764 \\
\hline William Aspinall & Will & Bonny & 84030 \\
\hline William Aspinall & Young William & Bonny & 84103 \\
\hline John Bolton & Governor Wentworth & Costa do Ouro & 81652 \\
\hline George Case & Active & Não disp. & 80025 \\
\hline George Case & Arthur Howe & Camarões & 80364 \\
\hline George Case & Aurora & Velho Calabar & 80401 \\
\hline George Case & Molly & Bonny & 82780 \\
\hline George Case & Nimble & Costa de Barlavento & 82948 \\
\hline George Case & Victory & Rio Congo & 83968 \\
\hline Charles Fairclough & Polly & África oriental, ocidental e central & 83138 \\
\hline Samuel Hinde & Agreeable & Bonny & 80125 \\
\hline Thomas Hinde & Diligent & Bonny & 81039 \\
\hline Brown Huson & Friendship & Não disp. & 81533 \\
\hline Brown Huson & Princess Amelia & Bonny & 83217 \\
\hline Gabriel James & Levant & Serra Leoa & 82249 \\
\hline Samuel McDowal & Annan & Costa do Ouro & 80307 \\
\hline John \& James Parr & Earl of Liverpool & Costa de Barlavento & 81116 \\
\hline Jonathan Ratcliff & Charles Hamilton & África oriental, ocidental e central & 83557 \\
\hline $\begin{array}{c}\text { Nicholas \& } \\
\text { Robert Vickers }\end{array}$ & Eliza & Não disp. & 81187 \\
\hline G. Preston, Winder & Prudence & África oriental, ocidental e central & 83250 \\
\hline
\end{tabular}

Fonte: Slave Voyages, “Trans-Atlantic Slaves Trade”; TNA, C 114/154, Journal of Thomas Lumley \& Co., 1801.

64 Os IDs de viagem na Tabela 1 são úteis para explorações adicionais sobre os detalhes de cada viagem, incluindo o número de escravos embarcados no navio. 
Fica claro na lista que os têxteis de algodão indianos foram embarcados de Liverpool para várias regiões da África atlântica depois de viajarem através de cadeias de redes do sul da Ásia via Londres para Liverpool. Um dos principais destinos mostrados na Tabela 1 é Bonny, na Baía de Biafra, o principal ponto de comércio que os britânicos utilizavam para a compra de escravos em meados do século XVIII. ${ }^{65}$ Embora a lista apresente apenas alguns casos de tráfico de escravos, ela sugere que alguns comerciantes tinham ligações com uma determinada região da África, ou mais de uma. Enquanto George Case negociava em vários locais na África Atlântica, a família Aspinall parecia ter uma forte ligação com Bonny ${ }^{66}$ Portanto, a Tabela 1 indica que os têxteis de algodão indiano fornecidos a partir de Londres contribuíram para Liverpool comerciar escravos no Atlântico e, assim, para as economias coloniais nas Américas.

\section{Conclusão}

A ligação econômica sul-sul discutida neste artigo foi representada por rotas comerciais imperiais de têxteis de algodão indianos que conectavam o sul da Ásia, através da Europa Ocidental, com a África atlântica, no século XVIII. Deve ser enfatizado que o estabelecimento de tais rotas estava associado à expansão dos primeiros impérios europeus modernos nos oceanos Atlântico e Índico. O comércio Europa-Ásia foi, portanto, crucial no fornecimento de tecidos de algodão indiano para o comércio de

65 Paul E. Lovejoy e David Richardson, “'This Horrid Hole’: Royal Authority, Commerce and Credit at Bonny, 1690-1840”, Journal of African History, v. 45, n. 3 (2004), pp. 363-392.

66 É interessante notar que sua rede de negócios com Bonny persistiu mesmo após a saída britânica do comércio de escravos, porque Bonny se tornou uma importante fonte de azeite de dendê para comerciantes britânicos, em particular de Liverpool, na primeira metade do século XIX. Durante esse período, a família Aspinall tornou-se um dos principais comerciantes de azeite de dendê em Liverpool, por meio do casamento com a família Tobin. Martin Lynn, "Trade and Politics in 19th-Century Liverpool: The Tobin and Horsfall Families and Liverpool's African Trade”, Transactions of the Historic Society of Lancashire and Cheshire, v. 142 (1993), p. 103. 
escravos do Atlântico e, assim, para as plantations e minas nas Américas. O papel significativo dos produtos asiáticos no comércio Atlântico revela a limitação do paradigma do comércio triangular.

Embora os comerciantes europeus fossem importantes para fazer a ligação econômica entre essas duas regiões, o vínculo econômico sul-sul mostra que seus negócios se articulavam entre os desejos dos consumidores africanos pelas mercadorias trazidas do exterior e a produção de indianos qualificados dos tipos de têxtil que eram demandados na África. Tanto a demanda do consumidor na África Atlântica como o desempenho dos tecelões indianos dependiam de uma variedade de fatores locais e, portanto, eram mutáveis. Em outras palavras, o desenvolvimento da economia escravista atlântica no século XVIII foi resultado do emaranhado desses diferentes protagonismos.

Recebido em 8 ago. 2020

Aprovado em 11 dez. 2020

doi: 10.9771/aa.v0i63.38307 
O século XVIII assistiu ao desenvolvimento da economia escravista atlântica, sustentada pela constante oferta de mão de obra do continente africano. Para comprar cativos africanos na costa do Atlântico, os mercadores estrangeiros tinham que atender às demandas expressas dos africanos, notadamente os tecidos indianos de algodão, que se tornaram o "carro-chefe" das mercadorias. Nesse período, o comércio anglo-asiático, conduzido pela Companhia Britânica das Índias Orientais, desempenhou um papel central no fornecimento de têxteis indianos para os comerciantes de escravos britânicos. Este artigo aborda como comerciantes britânicos adquiriam têxteis na Índia para a África Atlântica. Ao examinar essa questão, o artigo ilustra o comércio global de algodão, das áreas de produção de têxteis indianos para a África Atlântica, e, em última análise, argumenta que a narrativa do chamado "comércio triangular" precisa ser substituída por outra perspectiva, que destaque o protagonismo de consumidores africanos e de tecelões sul-asiáticos.

Comércio de escravos no Atlântico | Tecidos indianos de algodão | Companhia Britânica das Índias Orientais

\section{WEAVING IMPERIAL NETWORKS:}

\section{An Asian Dimension of the British Atlantic Slave Trade IN THE 18 TH CENTURY}

The eighteenth century saw the development of the Atlantic slave-based economy, sustained by a constant supply of labor from the African continent. On the Atlantic coast, in order to purchase captives foreign merchants had to meet local demands for trade commodities, notably Indian cotton textiles, which became a crucial product. During this period, the Anglo-Asian trade, conducted by the English East India Company, played a central role in the supply of Indian textiles for British slave traders. This paper addresses how British merchants procured textiles in India for Atlantic Africa. By examining this question, the paper illustrates a global cotton trade that extended between the areas where Indian textiles were produced and Atlantic Africa. Finally, the paper argues that the so-called "triangular trade" narrative should be replaced by another perspective that emphasizes the agency of African consumers and South Asian weavers.

Atlantic slave trade | Indian cotton textiles | English East India Company 